\title{
A Comparison of Underwater Gait Training with Additional Weight Application and Over-ground Gait Training to Improve Balance and Lower Extremity Strength in Persons with Stroke
}

\author{
Jae-Ho Park', Yijung Chung ${ }^{2}$ \\ 'Department of Physical Therapy, The Graduate School, Sahmyook University; ${ }^{2}$ Department of Physical Therapy, College of Health and Welfare, \\ Sahmyook University, Seoul, Korea
}

Purpose: This purpose of this study was to compare additionally applied weight underwater gait training and over-ground gait training to improve balance and lower extremity strength in stroke patients.

Methods: Subjects were randomly allocated into two groups. Underwater gait training group $(n=10)$ and Over-ground gait training group $(n=9)$. The groups performed their respective programs as well as conventional physical therapy 3 times/week for 6 weeks. All subjects were assessed with the Berg balance scale test, the timed up and go test, and the medical research council test pre and post intervention. A paired $t$ test was applied to compare the differences before and after the intervention, and an independent $t$ test was used to compare the differences between the groups. The level of statistical significance was set at $p<0.05$.

Results: The results showed that subjects in the underwater gait training group had a significantly increased Berg balance scale, timed up and go, and medical research council scores $(\mathrm{p}<0.05)$, and over-ground gait training group showed a significantly increased medical research council score $(p<0.05)$ after intervention. The underwater gait training group showed a more significant improvement in medical research council, Berg balance scale and the timed up and go test scores compared to the over-ground gait training group $(p<0.05)$. Conclusion: Findings of this study suggest that applying additional weight during underwater gait training improves lower extremity strength and balance in stroke patients. It' findings can contribute to the development of more efficient rehabilitation for stroke patients.

Keywords: Stroke, Rehabilitation, Gait, Balance

\section{INTRODUCTION}

Normal gait is defined as moving the weight centerline of the body effectively while using the minimum energy using harmonious movement of limbs. ${ }^{1}$ For this normal gait to be possible, there needs to be adequate coordination and interaction between various joints and muscles. However, in stroke patients, various compensatory mechanisms are mobilized to maintain functional gait due to difficulty in normal gait. These compensatory mechanisms exhibit abnormal gait form, which causes higher energy consumption and loss of efficiency compared to normal mechanisms. ${ }^{2}$ Also muscle weakness of the lower limbs in stroke patients is an element that limits functional restoration of the patient and muscle weakness

Received Mar 28, 2017 Revised Apr 26, 2017

Accepted Apr 27, 2017

Corresponding author Yijung Chung

E-mail yijung36@syu.ac.kr causes problems in maintaining balance and gait ability.,4

In order to resolve these problems, aquatic exercises can improve such things as range of joint motion, stiffness, relaxation, balance, and endurance without pain with various sensory stimulation using diverse properties of water, such as water temperature, buoyancy, hydrostatic pressure, and viscosity. ${ }^{5}$ Since the fear of falling is reduced, it is very useful in applying various postures and movements. ${ }^{6}$ Also, aquatic exercises provide a big therapeutic advantage in decreasing muscle tension and increasing stability and functional mobility for postural control. ${ }^{7}$ Previous study on underwater gait training compared to over-ground gait training showed an increase in the ratio of single limb stance phase of the affected side, an increase in the ratio of the swing phase on the non-affected side, a de-

Copylight (C2017 The Korea Society of Physical Therapy

This is an Open Access article distribute under the terms of the Creative Commons Attribution Non-commercial License (Http:// creativecommons.org/license/by-nc/4.o.) which permits unrestricted non-commercial use, distribution, and reproduction in any medium, provided the original work is properly cited. 
crease in the cycle of asymmetric gait, as well as a balanced gait pattern. ${ }^{8}$ A study that applied additional weight onto the affected side single limb reported that by minimizing the tendency of the affected side lower limb to float on water, it increased the stability of the stance phase and resulted in increasing the lower limb strength due to applying additional weight. As a result, study reported that weight-bearing was more effective, there was an increase in affected side lower limb percentage and an increase in the swing phase of non-affected side lower limb. ${ }^{9}$ Another previous study reported that additional weight application on stroke patients showed movement increase in the hip and knee joints, ${ }^{10}$ a increase in dorsiflexion of the ankles, increased flexor strength and movement range of joints during flexion of the lower limb in the swing phase of gait, and influenced activation of the extensor muscles during the stance phase of gait. ${ }^{11,12}$ These results show increasing capabilities with an increase in swing phase following hip joint flexor muscle activity increase. ${ }^{13}$

However, studies mentioned above are cross-sectional studies and not training studies, which is inadequate to testify about aquatic gait training with additional weight load applied onto stroke patients. In addition, most studies have focused on orthopedic patients, the elderly population, and normal, healthy people and there is lack of research with detailed data on balance abilities of patients with central nervous system diseases. Therefore, the study will provide a therapeutic basis for restoration of the weakened bodily function of stroke patients and thus balance ability and quality improvement as well as a rehabilitation method for improving lower limb strength through aquatic gait training. This study will explore the influence of aquatic gait training with additional weight load applied on balance and lower limb strength of stroke patients, and based on the results, the study will explore the usability of aquatic exercise therapy as a more effective method of rehabilitation exercise for stroke patients.

\section{METHODS}

\section{Subjects}

\section{1) Participants}

The nineteen subjects that participated in the study were from B Hospital in Gyeonggi-do, who had no more than 2 sessions of experience of participating in regular aquatic exercise therapy within the last 6 months, and before the experiment, agreements about the ex-
Table 1. Clinical characteristics of the participants in this study $(N=19)$

\begin{tabular}{lcccc}
\hline & $\begin{array}{c}\text { UWG group } \\
(\mathrm{n}=10)\end{array}$ & $\begin{array}{c}\text { OG group } \\
(\mathrm{n}=9)\end{array}$ & $\mathrm{X}^{2} / \mathrm{t}$ & $\mathrm{p}$ \\
\hline Age (yr) & $56.50 \pm 10.48$ & $57.22 \pm 16.96$ & 0.167 & 0.683 \\
Height (cm) & $160.50 \pm 0.20$ & $163.22 \pm 9.16$ & -0.533 & 0.814 \\
Weight (kg) & $66.72 \pm 6.13$ & $62.96 \pm 7.31$ & 1.322 & 0.202 \\
Gender & & & 0.560 & 0.814 \\
Male & 5 & 5 & & \\
Female & 5 & 4 & & \\
Paretic side & & & 0.056 & 0.814 \\
Right & 5 & 4 & & \\
Left & 5 & 5 & & \\
Type of stroke & & & 1.202 & 0.273 \\
Infarction & 3 & 5 & & \\
Hemormage & 7 & 4 & & \\
Duration (month) & $8.10 \pm 5.10$ & $10.11 \pm 2.08$ & 1.956 & 0.162 \\
MMSE (score) & $24.23 \pm 1.15$ & $26.00 \pm 2.39$ & 7.747 & 0.060 \\
MRC (score) & $16.10 \pm 1.28$ & $16.33 \pm 1.11$ & 0.820 & 0.680 \\
BBS (score) & $37.90 \pm 5.10$ & $39.67 \pm 7.29$ & 0.883 & 0.546 \\
TUG (sec) & $75.39 \pm 36.50$ & $55.53 \pm 32.06$ & 0.437 & 0.227 \\
\hline
\end{tabular}

Values are expressed as Mean \pm SD.

UWG: under water gait training, OG: over-ground gait training MMSE: mini mental state examination, MRC: medical research council, BBS: Berg balance scale, TUG: timed up and go test.

periment were obtained from the subjects. The experiment was conducted by randomly dividing the subjects into the underwater gait training group and the over-ground gait training group. Only those who provided written consent to participate were included. The inclusion criteria were as follows: (1) diagnosis of stroke (after minimum 6 months, minimize the possibility of natural restoration), ${ }^{14}$ (2) ability to walk 10 meters with or without an assistive device, (3) cognitive abilities enabling communication (minimum mini mental state examination score 22$),{ }^{7}$ (4) impairment of balance ability (maximum Berg balance scale score 45), (5) fearless of water, (6) medically stable and free of major cardiovascular or other medical conditions, (7) no history of orthopedic surgery within the past 6 months and seizure. All participants signed informed consent forms after receiving a detailed explanation of the study. The general characteristics of the participants are shown in Table 1.

\section{2) Protocol}

This study was a pretest and posttest with control group design for 6 weeks. The participants were randomly allocated to the additional weight underwater gait training (UWG) group and the overground gait training (OG) group. The UWG group performed un- 


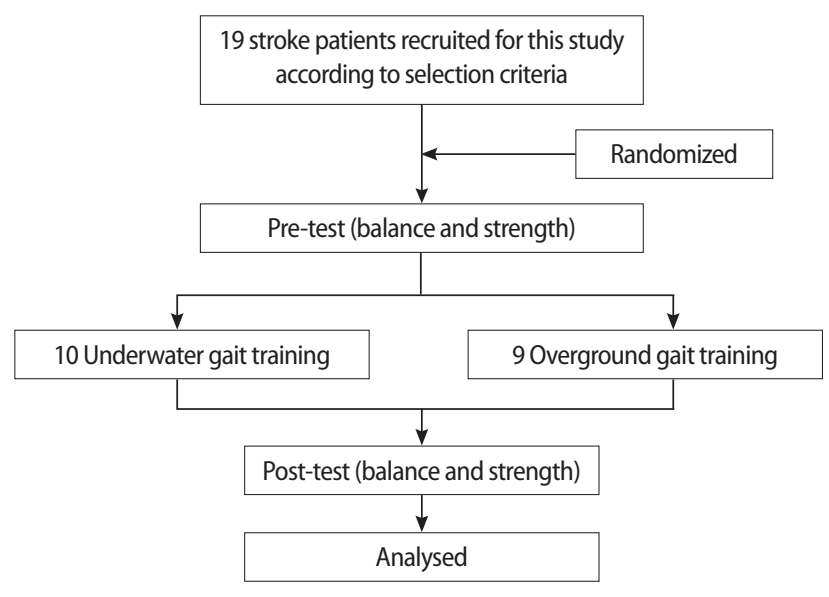

Figure 1. Enrollment of stroke patients.

derwater gait training with application of additional weight for 30 minutes per day, 3 times per week, for a total of 6weeks, while the OG group performed over-ground gait training for the same time period. In addition, all participants received conventional physical therapy 30 minutes per day, 5 times per week, for a total of 6 weeks. Balance ability and strength of UWG and OG were measured prior to the intervention. Also, to increase the reliability between the trainer and the evaluator, the training and evaluation was done by selecting physical therapists with at least 3 years of experience. After 6 weeks of training, the balance and strength of the UWG and OG were measured. For a single blind study, the research assistant and the trainer were different physical therapy personnel (Fig. 1).

\section{3) Intervention}

Underwater gait training involved wearing a 5\% body weight sandbag on the affected side ankle use of a metronome. During underwater gait training, gait training was conducted in a pool at chest height depth (xiphoid process) with water temperatures of 28 to $30^{\circ}$ $\mathrm{C}$, and for mediation of speed during gait training, researchers used metronomes to adjust the tempo to the subject's comfortable walking speed. On the first week of underwater gait training, considering safety first, a comfortable walking speed of each subject was measured underwater with use of metronome that correlated the tempo to the walking speed. In addition, the underwater gait training included subjects walking straight and in rotation. The space used for gait training was identical and training was conducted in a $4 \times 6 \mathrm{~m}$ aquatic exercise therapy room. On the third week, a 5\% increase in tempo from the subject's comfortable speed that was ob- tained from the first week was used to conduct the gait training. On the fifth week, the comfortable walking speed was measured and according to subject, an additional 5\% increase in tempo was applied according to the 5\% increased gait speed to conduct the gait training. The intervention periods for the subjects were 6 weeks, 3 times a week, for 30 minutes each. For subject safety, guidance during training was provided by physical therapists with 3 or more years of experience of aquatic exercise training and one assistant per subject as research assistants. Identical to underwater gait training, over-ground gait training measured come to walking speed on land without identical time and by using a metronome with the cadence, over-ground gait training was conducted.

\section{Experimental methods}

1) Measurement

\section{(1) Medical research council (MRC)}

MRC assesses the strength of the agonist and antagonist muscles of a variety of persons with neurological disease, including stroke. The MRC is divided into six grades: Normal (5), Good (4), Fair (3), Poor (2), Trace (1), Zero (0). Hip flexion, extension, abduction, knee flexion, extension, ankle dorsiflexion, plantar flexion of affected side lower extremity was assessed and was calculated as 0points out of a total of 35 points. The mean value was taken from three measurements, and to minimize the degree of fatigue, there was a 30 second rest period between measurements. ${ }^{15}$

\section{(2) The Berg balance scale (BBS)}

The Berg balance scale is an assessment of balance ability and consists of 14 items. It can be divided into three areas of sitting, standing and posture changes. It is scored with a maximum of 4 points and a minimum 0 points for each item, totaling up to 56 points for all 14 items. The time required to perform the entire item was defined as 15 minutes. The measurement tools of intra-rater reliability and inter-rater reliability is $r=0.99, r=0.98$ respectively, which indicates a high reliability and internal validity. In this study, we obtained the average value by measuring each of three times. ${ }^{16}$

\section{(3) The timed up and go test (TUG)}

The timed up and go test is evaluation of dynamic balance ability and functional mobility, and has shown a high degree of inter-examiner reliability $r=0.98$ and intra-rater reliability $r=0.99$. In addi- 
tion, it is shown to have a high correlation with walking speed and the BBS. In this study, a $46 \mathrm{~cm}$ height chair with armrests was placed on a flat surface. At first, subjects walked $3 \mathrm{~m}$ round-trip. Subjects performed this test three times and the average of the measured values was obtained. ${ }^{17}$

\section{2) Data analysis}

The descriptive statistics, tests for normality (Shapiro-Wilk Test), and homogeneity of variance were calculated as the outcome vari ables using SPSS 19.0 software for Windows (SPSS Inc., Chicago, IL, USA). An independent two-sample t-test was used because of the homogeneity of the subjects, and Paired t-tests were used to evaluate differences before and after treatment. Independent t-tests were performed to determine the significance of differences between groups. The level of significance was set at $\mathrm{p}<0.05$.

\section{RESULTS}

\section{General characteristics and homogeneity test of participants}

The homogeneity test of the general characteristics and medical characteristics of the 2 groups showed no significant differences in all characteristics between groups (Table 1).

\section{Changes in muscular strength and balance ability}

The muscular strength of the UWG increased significantly after training $(\mathrm{p}<0.05)$. UWG showed a significant increase in MRC scores from 16.10 to 18.30 and the OG also showed a significant increase from 16.33 to 17.11 ( $\mathrm{p}<0.05)$. The balance ability of UWG increased significantly after training $(\mathrm{p}<0.05)$. For BBS scores, the UWG showed a significant increase from 37.90 points before experiment and 45.70 points after experiment $(\mathrm{p}<0.05)$, and OG did not show significant differences before and after the experiment $(\mathrm{p}<0.05)$. For TUG elapsed time of the UWG, there was significant decrease from 75.39 seconds before experiment to 49.10 seconds after experiment $(\mathrm{p}<0.05)$. On the other hand, there were no significant differences shown in the OG $(\mathrm{p}<0.05)$. Also, the UWG showed significant improvement effects in the variation of MRC, BBS, and TUG scores after treatment compared to the OG $(\mathrm{p}<0.05)($ Table 2).

\section{DISCUSSION}

This study was conducted to compare the influences on balance ability according to changes in lower limb strength changes when conducting 6 weeks of applying additional weight during underwater gait training and to suggest an exercise method for functional improvement in persons affected by stroke. After the intervention, the UWG showed significant improvements in lower limb strength, BBS, and TUG scores, compared to the OG $(\mathrm{p}<0.05)$.

Stroke patients generally show a decrease in the ratio of single limb standing in stride length and stance phase in the affected side lower limb and it represents a decrease of joint angle at the hip and knee joint. As a result, gait speed is decreased, and due to inappro-

Table 2. Changes in muscle strength and balance in this study $(\mathrm{N}=19)$

\begin{tabular}{|c|c|c|c|c|c|c|}
\hline & \multicolumn{2}{|c|}{ UWG group $(n=10)$} & \multicolumn{2}{|c|}{ OG group $(n=9)$} & \multirow{2}{*}{$\mathrm{t}$} & \multirow{2}{*}{$\mathrm{p}$} \\
\hline & Pre-test & Post-test & Pre-test & Post-test & & \\
\hline \multicolumn{7}{|l|}{ Strength } \\
\hline MRC & $16.10 \pm 1.28$ & $18.30 \pm 0.82$ & $16.33 \pm 1.11$ & $17.11 \pm 0.78$ & 2.262 & 0.005 \\
\hline Difference (post-pre)(t) & $2.20 \pm 1.03(-6.736)$ & & $0.77 \pm 0.66(-3.500)$ & & & \\
\hline $\mathrm{p}$ & 0 & & 0.008 & & & \\
\hline \multicolumn{7}{|l|}{ Balance } \\
\hline BBS & $37.90 \pm 5.10$ & $45.70 \pm 3.80$ & $39.67 \pm 7.29$ & $41.44 \pm 8.48$ & 0.769 & 0.007 \\
\hline Difference (post-pre)(t) & $7.80 \pm 4.10(-6.010)$ & & $1.77 \pm 3.99(-1.336)$ & & & \\
\hline $\mathrm{p}$ & 0 & & 0.218 & & & \\
\hline TUG & $75.39 \pm 36.50$ & $49.10 \pm 24.66$ & $55.52 \pm 32.06$ & $50.63 \pm 28.58$ & 6.72 & 0.011 \\
\hline Difference (post-pre)(t) & $-26.28 \pm 22.25(3.735)$ & & $-4.89 \pm 8.49$ & & & \\
\hline$p$ & 0.005 & & 0.122 & & & \\
\hline
\end{tabular}

Values are expressed as Mean \pm SD.

UWG: under water gait training, OG: over-ground gait training, MMSE: mini mental state examination, MRC: medical research council, BBS: Berg balance scale, TUG: timed up and go test. 
priate weight bearing onto the affected side, an asymmetric gait form is displayed. ${ }^{18}$ Because of this change, persons with stroke generally show an increase in risk of falling with asymmetrical balance ability. ${ }^{19,20}$ For this reason, recently various rehabilitation programs are being applied to recover the function and walking ability of stroke patients. In the study by Hesse et al., ${ }^{8}$ it was found that partial weight support treadmill training increased the ratio of symmetrical stance and swing phase in the affected and non-affected side according to the increase of ratio of single limb standing and swing phase.

Aquatic exercises also were advantage of can be conducted without the fear of falling by using characteristics of water to conduct gait training. ${ }^{21,22}$ A study by Bale et al. ${ }^{23}$ showed an increase in the weight support ratio of the affected side during standing through functional strengthening training as well as balance ability improvement. In the study by Noh et al., ${ }^{14}$ compared to common physical treatment, including an aquatic program for stroke patients showed a significant increase in BBS scores. Because of aquatic environment has reduced gravity and make movement easier than when on land. It also provides a sense of physical stability due to the influence of buoyancy, which makes the patients perform more challenging tasks better than when on land. ${ }^{24}$ The results of this study also show that the experimental group performing underwater gait training significantly increased the balance ability compared with the control group performing ground based training. This was in agreement with previous studies, which showed significant improvement not only in balance ability but also in muscle strength.

Wolfson et al. ${ }^{25}$ reported that loss of balance ability in stroke patients was related to weakening of ankle strength. When there is rigidity of the plantar flexors of the ankles, at the start of the stance phase, the heel does not contact the ground and the tip or sole contacts first, which decreases the stance phase and due to difficulty in push-off. During the swing phase, the hip and knee joints are excessively bent to move forwards to prevent foot-drop, and this type of line walking decreases walking speed, leading to an inefficient gait. Therefore, there is a need for balance restoration through lower limb muscle strengthening for effective movement in stroke patients. A study by Lam et al. ${ }^{13}$ reported that additional weight application on stroke patients showed increased flexor strength during flexion of the lower limb in the swing phase of gait, and influenced activation of the extensor muscles during the stance phase of gait.
In the study, as a result of conducting a repetitive aquatic exercise program with additional weight applied onto the affected side lower limb, it is determined that based on the increase of affected side lower limb strength and stability influenced balance ability improvement. In addition, one of the advantages of gait training underwater is the presence of buoyancy, which is one of the basic properties of water, because it decreases pressure onto the joints which enables gait training with less strength requirements compared to land and it is determined that benefit from the water properties such as the result of increasing the ratio of affected side single limb standing and swing phase during gait training also influences balance ability. ${ }^{8,23,24}$ The results of this study MRC score showed that UWG had significant differences compared to the OG $(\mathrm{p}<0.05)$. Also for the affected side weight load aquatic exercise group, it is considered that it is the result of lower limb stability increase following lower limb strength increase and affected side lower limb stance phase ratio increase. ${ }^{9}$ However, the control group also showed improvement in lower extremity strength, but did not show a significant difference in balance ability. A study by Kim et al., ${ }^{26}$ has reported that aquatic exercise has a great influence on the psychological part such as the confidence of the balance. It is thought that this evidence had a great influence on the results.

A study by Yoshihiro et al., ${ }^{27}$ has reported that after aquatic gait training of 8 weeks on normal elderly subjects, the result value of the TUG was significantly decreased and also in the study by Jamile Vivas et al. ${ }^{7}$ there was a similar result that the TUG result value was 16.87 seconds before experiment and 15.21 seconds after experiment. Like this, it was mentioned that aquatic exercise increases stability based on lower limb strength increase of stroke patients to bring improvements in balance ability. ${ }^{9}$ From a clinical perspective, improvement in gait ability is the main interest of stroke patient rehabilitation research and among it, gait speed is used as an index to show the level of independent capability that can conduct everyday life and function restoration. ${ }^{28}$ Recently, there are many reports of studies about influence of applying aquatic gait training on stroke patients. Jung et al. ${ }^{9}$ conducted movement analysis after conducting aquatic treadmill training with affected side ankle weight load application as a cross-sectional study and as a result, during aquatic treadmill training with weight load application, compared to the control group, the weight load group showed increase of stability in the affected side lower limb. In the study by Park et al. ${ }^{29}$ there was a 
significant improvement in gait speed in the result of gait analysis through comparison of aquatic treadmill and general treadmill training, and there was better improvement of stability in the single limb standing of the affected side lower limb compared to the general treadmill group. A study by Lam et al. $1^{3}$ showed an average increase of $8.5 \mathrm{~cm} / \mathrm{s}$ in gait speed in the result of treadmill training after applying an additional weight load on the affected side ankle, and in the study by Regnaux et al. ${ }^{30}$ it was reported that an average of $6 \mathrm{~cm} / \mathrm{s}$ gait speed improvement was represented after conducting contralateral side lower limb weight load treadmill gait training. In the movement analysis of aquatic gait training in the study by Barela et al., ${ }^{31}$ it was reported at there was increase of muscle activity in the stance phase in the tensor fasciae latae muscle, vastus lateralis muscle, and biceps femoris muscle. Based on this evidence, the study also considers that increase in activity of the hip flexor muscles will bring increase in gait speed according to the increase of balance ability improvement and stance phase ratio based on affected side lower limb stability of stroke patients. Also, due to buoyancy and water resistance, aquatic gait training promotes strengthening of the rectus femoris, biceps femoris, and vastus medialis and increases in gait stability and thus, increases gait speed. ${ }^{30,31}$ Also, due to buoyancy in aquatic gait, body weight support is easy provides psychological comfort which is considered to influence the improvement in balance and gait ability. ${ }^{6,32}$

Our results suggest that applying additional weight during underwater gait training improves lower extremity strength and balance in stroke patients. And it' findings can contribute to the development of more efficient rehabilitation for stroke patients. But, this study has some limitations in interpreting the results. First, all of our study participants were condition of independent walking (with aid or without aid). This condition is insufficient to replace the judgment of the degree of recovery of a patient who has difficulty in walking independently. Second, given the sample size of experimental study was little. So generalizing the results is difficult. Third, the evaluation index of this study is limited to the balance ability and strength, so it is not sufficient to evaluate the walking ability. In future studies, there is a need for supplementation and development on task-oriented repetitive aquatic gait training and aquatic exercise programs through exercise plans and program supplements appropriate to various patients, including stroke patients.

\section{REFERENCES}

1. Perry J. Gait analysis : normal and pathological function. Thorofare, Slack, 1992.

2. Smith LK, Weiss EL. Brunstron's clincal kinesiology. 5th ed. Philadephia, F.A. Davis Company, 1996.

3. Park JJ, So HJ, Shin WS. Effects of gluteus medius strengthening training using pressure biofeedback unit for muscle function and balance in stroke patients. J Kor Phys Ther. 2015:27(4):221-7.

4. Park JH, Kim YM, Lee NK. The effects of repetitive sit-to-stand training with a paretic-side asymmetrical foot position on the balance of chronic stroke subjects. J Kor Phys Ther 2015:27(3):169-73.

5. Becker BE. Biophsiologic aspets of hydrotherapy. In: Berker BE, eds, Comprehensive Aquatic therapy, Boston, Butter-Warth- Heinemann, 1997:17-48.

6. Park SK, Yang DJ, Kang JI et al. The effects of water-based exercise on muscle activity and gait ability in stroke patients. J Kor Phys Ther. 2015; 27(5):369-74.

7. Vivas J, Arias P, Cudeiro J. Aquatic therapy versus conventional landbased therapy for Parkinson's disease: an open-label pilot study. Arch Phys Med Rehabil. 2011;92:1202-10.

8. Hesse S, Konrad M, Uhlenbrock D. Treadmill walking with partial body weight support versus floor walking in hemiparetic subjects. Arch Phys Med Rehabil. 1999;80:421-7.

9. Jung T, Lee D, Charalambous $\mathrm{C}$ et al. The influence of applying additional weight to the affected leg on gait patterns during aquatic treadmill walking in people post-stroke. Arch Phys Med Rehabil. 2010;91:129-36.

10. Hidler JM, Carroll M, Federovich EH. Strength and coordination in the paretic leg of individuals following acute stroke. IEEE Trans Neural Syst Rehabil Eng. 2007;15(4):526-34.

11. Duysens J, Clarac F, Cruse H. Load-regulating mechanisms in gait and posture: comparative aspects. Physiol Rev. 2000;80:83-133.

12. Lam T, Wolstenholme C, Yang JF. How do infants adapt to loading of the limb during the swing phase of stepping? J Neurophysiol. 2003;89(4): 1920-8.

13. Lam T, Luttmann K, Houldin A et al. Treadmill-based locomotor training with leg weights to enhance functional ambulation in people with chronic stroke: a pilot study. J Neurol Phys Ther. 2009;33(3):129-35.

14. Noh DK, Lim JY, Shin HI et al. The effect of aquatic therapy on postural balance and muscle strength in stroke survivors-a randomized controlled pilot trial. Clin Rehabil. 2008,22(10-11):966-76.

15. Gregson JM, Leathley MJ, Moore AP et al. Reliability of measurements of muscle tone and muscle power in stroke patients. Age Ageing. 2000; 29(3):223-8.

16. Berg K, Wood-Dauphinee S, Williams JI. The balance scale: reliability assessment with elderly residents and patients with an acute stroke. Scand J Rehabil Med. 1995;27(1):27-36.

17. Podsiadlo D, Richardson S. The timed "Up \& Go": a test of basic functional mobility for frail elderly persons. J Am Geriatr Soc. 1991;39(2): $142-8$.

18. Park SK, Kim JH. Effects of isokinetic eccentric training on lower extremity muscle activation and walking velocity in stroke patients. J Kor Phys Ther. 2015;27(4):190-5.

19. Hwang DG, Kim JH. Relation between weight bearing ratio in the 
standing posture immediately after performing standing task and balance and functional ambulation in stroke patients. J Kor Phys Ther. 2015:27(5):320-4.

20. Yang DJ, Park SK, Kang JI et al. Effects of game based weight-bearing training on lower extremity muscle activation and balance in stroke patients. J Kor Phys Ther. 2015;27(4):264-9.

21. Suomi R, Koceja DM. Postural sway characteristics in women with lower extremity arthritis before and after an aquatic exercise intervention. Arch Phys Med Rehabil. 2000;81:780-5.

22. de Oliveira CB, de Medeiros IR, Frota NA et al. Balance control in hemiparetic stroke patients: main tools for evaluation. J Rehabil Res Dev. 2008;45(8):1215-26.

23. Bale M, Strand LI. Does functional strength training of the leg in subacute stroke improve physical performance? a pilot randomized controlled trial. Clin Rehabil. 2008;22(10-11):911-21.

24. Masumoto K, Shono T, Hotta N et al. Muscle activation, cardiorespiratory response, and rating of perceived exertion in older subjects while walking in water and on dry land. J Electromyogr Kinesiol. 2008;18(4): 581-90.

25. Wolfson L, Judge J, Whipple R et al. Strength is a major factor in balance, gait, and the occurrence of falls. Health Soc Work. 1995;50:64-7.
26. Kim SH, Lee DK, Kim EK. (2014). Effect of aquatic exercise on balance and depression of stroke patients. J Kor Phys Ther. 2014;26(2):104-9.

27. Katsura Y, Yoshikawa T, Ueda SY et al. Effects of aquatic exercise training using water-resistance equipment in elderly. Eur J Appl Physiol. 2010; 108:957-64.

28. Ada L, Dean CM, Hall JM et al. A treadmill and overground walking program improves walking in persons residing in the community after stroke: a placebo-controlled, randomizedtrial. Arch Phys Med Rehabil. 2003;84(10):1486-91.

29. Park SE, Lee ME, Yoon BC et al. Comparison of underwater and overground treadmill walking exercise to improve gait and physical function in people after stroke. J Int Acad Phys Ther Res. 2010;1:120-5.

30. Regnaux JP, Pradon D, Roche N et al. Effects of loading the unaffected limb for one session of locomotor training on laboratory measures of gait in stroke. Clin Biomech(Bristol, Avon). 2008;23(6):762-8.

31. Barela AM, Stolf SF, Duarte M. (2006). Biomechanical characteristics of adults walking in shallow water and on land. J Electromyogr Kinesiol. 2006;16(3):250-6.

32. Lim HS, Lee SM. The effect of a water exercise on gait characteristics in the elderly post stroke patients. Phys Ther Rehabil Sci. 2012;1(1): 17-21. 